\title{
Content Areas covered within the Case Studies
}

In order to gain accreditation through the Foundation Programmes, every student must have experience of all seven areas of common content during their two year programme. Experience of developing programmes for accreditation would indicate that the most effective way to ensure that all the requirements are met for each individual student, without extensive monitoring, is by ensuring that each module delivers all seven content areas.

To assist in the development of a broad and balanced programme the content is checked for each Case Study using the seven common areas identified by the Joint Unit. The balance of emphasis of the Case Study is also indicated by coding the content coverage as indicated below.

\section{CHECKLIST OF CONTENT COVERED BY CASE STUDIES IN THIS PACK}

The content areas covered in the Case Study are coded using the following key:
KEY: a. Touched on
b. Covered in one task
c. Developed in a number of tasks
d. The focus of the Case Study

\begin{tabular}{|c|c|c|c|c|c|c|c|c|c|c|c|c|c|c|c|c|}
\hline \multirow[b]{2}{*}{ Content Area } & \multicolumn{16}{|c|}{ Case Study Number } \\
\hline & 1 & 2 & 3 & 4 & 5 & 6 & 7 & 8 & 9 & 10 & 11 & 12 & 13 & 14 & 15 & 16 \\
\hline $\begin{array}{l}\text { Lifestyles and } \\
\text { Relationships }\end{array}$ & $\mathbf{a}$ & $\mathrm{d}$ & $b$ & c & c & & $b$ & $\mathrm{a}$ & c & & & & $\mathrm{d}$ & d & $\mathrm{d}$ & $\mathrm{d}$ \\
\hline Organisations & $a$ & a & a & d & $\mathrm{d}$ & & b & c & & c & & c & d & $\mathrm{d}$ & $\mathrm{c}$ & d \\
\hline Material Resources & d & b & b & $\mathrm{d}$ & $\mathbf{a}$ & d & $\mathrm{d}$ & $\mathrm{d}$ & $\mathrm{d}$ & $\mathrm{d}$ & $\mathrm{d}$ & d & $\mathrm{d}$ & d & d & $\mathbf{a}$ \\
\hline $\begin{array}{l}\text { Techniques of } \\
\text { Communication }\end{array}$ & $\mathrm{d}$ & $b$ & $b$ & $b$ & c & b & b & $\mathrm{d}$ & a & c & c & c & $\mathrm{d}$ & d & $\mathrm{d}$ & $\mathrm{b}$ \\
\hline $\begin{array}{l}\text { Personal Welfare, Health } \\
\text { and Safety }\end{array}$ & $\mathbf{a}$ & d & & $\mathrm{b}$ & a & $\mathrm{b}$ & a & a & & a & a & $a$ & c & $\mathrm{b}$ & $\mathrm{b}$ & $\mathrm{d}$ \\
\hline The Environment & d & $\mathrm{d}$ & $\mathrm{d}$ & $b$ & b & & $\mathrm{a}$ & b & $\mathrm{a}$ & & & & $a$ & & c & a \\
\hline $\begin{array}{l}\text { The Aesthetic/Cultural } \\
\text { Environment }\end{array}$ & $\mathrm{d}$ & & $\mathrm{d}$ & $a$ & a & b & $b$ & a & $\mathrm{a}$ & & $\mathrm{a}$ & & $a$ & c & $\mathrm{d}$ & $\mathrm{b}$ \\
\hline
\end{tabular}

